\title{
Relation between Risk Factors of Pyoderma and Pyoderma Incidence
}

\author{
Lila Indria Depari, ${ }^{1}$ Unwati Sugiri, ${ }^{2}$ Lola Ilona ${ }^{3}$ \\ ${ }^{1}$ Faculty of Medicine Universitas Padjadjaran, ${ }^{2}$ Department of Dermato-venerology Faculty of \\ Medicine Universitas Padjadjaran/Dr. Hasan Sadikin General Hospital, Bandung, ${ }^{3}$ Department of \\ Epidemiology and Biostatistic Faculty of Medicine Universitas Padjadjaran
}

\begin{abstract}
Background: Pyoderma is a purulent bacterial infection of the skin. In developing countries, pyoderma is the most common skin disease in children. Pyoderma attacks male more often than female. Factors influencing pyoderma are low socioeconomic level, low education, low personal hygiene and unhygienic house. This study was conducted to assess the relation between risk factors of pyoderma and pyoderma incidence.

Methods: This study used cross-sectional study design and was conducted from August-November 2013. The sample collection was done with multistage random sampling, where 196 primary school children in Jatinangor subdistrict were randomly taken to be admitted into this study. The data collection procedure consisted of physical examination and questionnaire filling. The data were statistically analyzed using independent $\mathrm{T}$ and chi-square test.

Results: Upon examining 196 subjects, four were found with pyoderma. As such, the prevalence of pyoderma on primary school children in Jatinangor in 2013 was $2 \%$. There was relation between personal hygiene and pyoderma incidence $(p=0.041)$. Sex $(p=0.623)$, healthy housing $(p=0.097)$, socioeconomic level $(p=0.742)$ and education level of parents $(\mathrm{p}=0.989)$ were not related with pyoderma.

Conclusions: Personal hygiene is the risk factor that had relation with incidence of pyoderma. [AMJ.2016;3(3):434-39]
\end{abstract}

Keywords: Personal hygiene, pyoderma, risk factors

\section{Introduction}

Pyoderma is a purulent bacterial infection of the skin. Pyoderma can be classified into primary and secondary types. ${ }^{1}$ Within bacterial skin disease, primary and secondary pyoderma are the most common condition. Based on 18 prevalence studies in developing countries, all reported that pyoderma was the most common skin disease in children $(0.2-35 \%)$. The prevalence of pyoderma in Indonesia was $1.4 \%$ on adults, and $0.2 \%$ on children. $^{2}$ Pyoderma is most prevalent in the age group of below 10 years old $(48 \%))^{3}$ Studies about skin disorder prevalence in elementary schools in Kerala ${ }^{4}$ stated that the prevalence of pyoderma on elementary school students was $4.2 \%$. Pyoderma attacks male more often than female., ${ }^{2,3,5}$

Factors influencing pyoderma are low education, low socioeconomic level, low personal hygiene and unhealthy house. . $^{2,6,7}$ Low levels education may contribute to the low level of socio-economic families. ${ }^{8}$ Pyoderma is more frequent on the lower social-economic class. ${ }^{2,3}$ Low socioeconomic level will cause low nutrient intake, hence causing the immune system of the body decrease. Lower body immune has higher chance of getting skin infection. Low socioeconomic level can also cause a person to live in unhygienic home and crowded environment. ${ }^{6}$ Previous study stated that most of the subjects who suffered pyoderma lived in unhygienic house or environment (43.3\%) and had poor personal hygiene $(66.7 \%) .^{7}$ Poor personal hygiene facilitates colonization, infection, and transmission of Staphylococcus aureus, as a causative organism of pyoderma. ${ }^{9}$ Since there was insufficient data about pyoderma in Jatinangor sub district, this study was conducted to assess the relation between risk factors of pyoderma and pyoderma incidence.

\section{Methods}

This study used a cross-sectional study design.

Correspondence: Lila Indria Depari, Faculty of Medicine, Universitas Padjadjaran, Jalan Raya Bandung-Sumedang Km.21, Jatinangor, Sumedang, Indonesia, Phone: +62 85774478892 Email: lila_indria@yahoo.co.id 
The population was primary school children in Jatinangor sub district, in the academic year of 2013-2014. This study was conducted on 4 state primary schools in Jatinangor. The study was conducted from August-November of 2013.

The sample collection was done with multistage random sampling. From 12 village in Jatinangor subdistrict, Cipacing village was randomly selected. There were four elementary schools in Cipacing village, where 196 students were randomly taken from those 4 elementary schools to be admitted into this study. Inclusion criteria was students of first through third grade of the state primary school in the sub district of Jatinangor. Students aged 6-10 years old were consented to the study with permission from the headmaster to become a subject of this study. While the exclusion criteria was nonattendance at the time of physical examination.

Before the data were collected, informed consent was obtained. The subjects of this study had the right to agree or disagree on admitting into the study. This study had been approved by Health Research Ethics, the local directorate of education, and the headmaster.

The data collection procedure in this study consisted of physical examination and questionnaire filling. Physical examination was conducted on the subjects. The examination was done in enclosed room which were attended by the researcher, the dermatologist and a teacher to accompany the subjects. At the time of examination, all subjects were asked to take off all of their clothes so that all parts of their body can be examined. Physical examination was done accompanied by a dermatologist. The aim of the physical examination is to support the diagnosis of pyoderma on subjects.

A questionnaire containing closed questions was designed. Data of the questionnaire consisted of personal hygiene, socioeconomic level, home hygiene, parents' level of education, as well as identity of the subjects consisted of age and sex. The questionnaire was subjected to a pilot trial on 30 parents for content validation purpose before it was distributed to the parents of the subjects. Questionnaire filling was done by the parents of the subjects. Questionnaire was given to the parents in two ways, first as directly from the researcher to the parents who accompanied their children to school, the second was to ask the subjects to give the questionnaire to their parents and to bring the questionnaire back in one to two weeks. All questions on the form had to be answered.

Socioeconomic level was calculated from the monthly income of parents. High socioeconomic level was stated when the monthly income is more or equal with minimal wage rate of the sub district of Sumedang, which was $\operatorname{Rp} 1,380,000.00$. For the personal hygiene of the subjects, a calculation of three hygiene scores were conducted. Hygiene score consisted of daily frequency of handwashing ( $1=<6$ times, $2=6-12$ times, $3=>12$ times), number of personal items being shared with other people ( $1=\geq 2$ items, $2=1$ item, $3=$ none) and weekly frequency of bathing $(1=<7$ times, $2=7-13$ times, $3=>13$ times). A poor personal hygiene was stated when the sum of those three scores is less or equal with $6 .^{10}$

Home hygiene was assessed with three aspects of scoring, which consisted of the components of house, sanitation and behavior. A house would be categorized into hygienic house when it reached score of 1068-1200. This hygienic house scoring was based on the Technical Guide to Assess Healthy Houses, by the Ministry of Health Indonesia in 2012.

Primary data of every subject that have been collected would be processed and analyzed using computerized statistical programs. Personal hygiene and hygienic house data were statistically analyzed using independent T-test. Sex, socioeconomic level and parents' education level data were statistically analyzed using chi-square test. Statistically significant was determined when $\mathrm{p} \leq 0.05$

\section{Results}

The result of the study was obtained from questionnaire filling and physical examination on 196 students from the first through the third grade of primary schools in Jatinangor. Most of the study subjects were boys. The age range for subjects was 6-10 years old, averaging at 7.15 years old. Most of the subjects had a low socioeconomic level (56.6\%). The level of education on the parents was dominated by high school graduate (44.9\%). From 196 research subjects, only few had poor personal hygiene (34.2\%) and unhygienic houses (46.4\%) (Table 1).

Upon examining 196 subjects, four were found with pyoderma. As such, the prevalence of pyoderma on primary school students on elementary school students from first through third grade in the Jatinangor sub district in 2013 was $2.0 \%$. Seen from a clinical presentation of pyoderma subjects, the types of pyoderma found in this study was 
ecthyma ( 3 cases), bullous impetigo (1 case) and folliculitis (1 case). From four subjects who were found with pyoderma in physical examination, most suffered from the ecthyma type. The most commonly found location of pyoderma was the lower extremity (3 cases).

There was no relation between sex and pyoderma $(\mathrm{p}=0.623)$. Most of subjects with and without pyoderma in this study were male. Education level of parents was also not related with pyoderma incidence $(\mathrm{p}=0.989)$. Most of education level of parents in subject with and without pyoderma was senior high school. Based on chi-squared test, there was no relation between socioeconomic level and pyoderma ( $p=0.742)$. Socioeconomically, most subject with and without pyoderma had low socioeconomic level (Table 2).

According to independent T-test, personal

\section{Table 1 Respondent Characteristic}

\begin{tabular}{lc}
\hline \multicolumn{1}{c}{ Variable } & n (\%) \\
\hline Age (years old) & $50(25.5)$ \\
6 & $78(39.8)$ \\
7 & $57(29.1)$ \\
8 & $10(5.1)$ \\
9 & $1(0.5)$ \\
10 & \\
Sex & $103(52.6)$ \\
Male & $93(47.4)$ \\
Female & \\
Socioeconomic level & $111(56.7)$ \\
Low & $85(43.3)$ \\
High & \\
Education level of parent & $0(0.0)$ \\
Not going to school & $43(21.9)$ \\
Elementary school & $49(25.0)$ \\
Junior high school & $88(44.9)$ \\
Senior high school & $16(8.2)$ \\
College & \\
Personal hygiene & $129(65.8)$ \\
Good & $67(34.2)$ \\
Poor & \\
Healthy housing & $105(53.6)$ \\
Healthy & $91(46.4)$ \\
Unhealthy & \\
\hline &
\end{tabular}

hygiene was related with pyoderma incidence $(\mathrm{p}=0.041)$. Subjects with pyoderma had lower mean of personal hygiene score. However, this study also found that there was no relation between healthy housing and pyoderma incidence $(\mathrm{p}=0.097)$.

\section{Discussion}

This study found that the prevalence of pyoderma in the primary school children was $2.0 \%$. This prevalence was still higher than the World Health Organization (WHO) reference on the prevalence of pyoderma among Indonesian children in Sumatra of $0.2 \%{ }^{2}$ Higher prevalence in this study might be caused by the low socioeconomic and poor hygiene level of subject in this study. But the prevalence of this study was lower than the previously reported prevalence among elementary school students in Arab Saudi ${ }^{11}$ (11.6\%) and in Kerala $^{4}(4.2 \%)$. This was probably due to most of the subjects having good personal hygiene and hygienic houses. Apart from that, all the subjects from pyodema prevalence research in Saudi Arabia ${ }^{11}$ were male. Therefore, higher prevalence of pyoderma was possible to be achieved compared to the prevalence of pyoderma achieved in this study, because pyoderma occured mostly in male compared to female.,3

This study showed there was no relationship between sex and pyoderma. Khalifa et al. ${ }^{8}$ study, among primary school children in Baghdad, was also mentioned that there was no significant sex variations in the prevalence of skin diseases, included pyoderma $(\mathrm{p}=0.74)$. Pyoderma in this study was more common in male than female. This results supported the previous study conducted by Gandhi et al. ${ }^{3}$ in India and data $\mathrm{WHO}^{2}$

Personal hygiene was related to pyoderma incidence in this study. This result supported the previous studies by Sutisna et al. ${ }^{7}$ who conducted a study in Sultan Agung hospital, in Indonesia. The study also showed that there was association between personal hygiene and pyoderma $(\mathrm{p}<0.05)$. Study conducted by El Gilany et al. ${ }^{12}$ in Mansoura University Hospital, stated that furunculous recurrence was associated with poor personal hygiene. Study in $\mathrm{Mali}^{2}$ also stated that there was significant correlation between personal hygiene and pyoderma (odd ratio $=1.68$ ). The study about effect of handwashing on child health said about incidence of impetigo was 36\% lower in children that received antibacterial soap and taking a bath every day. ${ }^{13}$ According to 
Table 2 Relation between Sex, Socioeconomic Level and Education Level of Parents and Pyoderma Incidence

\begin{tabular}{lccc}
\hline \multicolumn{1}{c}{ Characteristic } & $\begin{array}{c}\text { Pyoderma (+) } \\
(\mathbf{n}=\mathbf{4}) \\
\mathbf{n}\end{array}$ & $\begin{array}{c}\text { Pyoderma (-) } \\
(\mathbf{n = 1 9 2 )} \\
\mathbf{n ( \% )}\end{array}$ & $\mathbf{p}$ \\
\hline Sex & 3 & $100(97.1)$ & 0.623 \\
$\quad$ Male & 1 & $92(98.9)$ & \\
$\quad$ Female & & & \\
Socioeconomic level & 3 & $108(97.3)$ & \\
$\quad$ Low & 1 & $84(98.8)$ & \\
High & & 0.742 \\
Education level of parent & 0 & $43(100)$ & \\
$\quad$ Not going to school & 0 & $48(98.0)$ & \\
$\quad$ Elementary school & 1 & $85(96.6)$ & \\
Junior high school & 3 & $16(100)$ & \\
Senior high school & 0 & & \\
College & &
\end{tabular}

data WHO in 2005, higher use of water for washing was associated with reduced rate of impetigo (odd ratio $=0.45$ ). ${ }^{2}$ Poor personal hygiene facilitates colonization, infection, and transmission of Staphylococcus aureus, as a causative organism of pyoderma. ${ }^{1,2,9}$ Most children with pyoderma in this study had a poor level of personal hygiene and most children without pyoderma had good personal hygiene. Research in Guwahati conducted by Hazarika et al. ${ }^{14}$ also said that $48.0 \%$ of children with pyoderma had a poor level of hygiene.

This study revealed that there was no relation between hygienic housing and pyoderma. This result was slightly different from the previous study conducted by Sutisna et al. ${ }^{7}$ in Sultan Agung hospital, in Indonesia. That study mentioned that there was significant correlation between environmental hygiene with pyoderma $(p<0.05)$ and most of the subjects who suffer pyoderma were having an unhygienic house or environment. ${ }^{7}$ It might be caused by the different study design that used to find the relation between hygienic house and pyoderma. Sutisna et al. ${ }^{7}$ study used casecontrol study design. According to Indonesia Health Profile in 2010, hygienic housing was also influenced by house density level. ${ }^{15}$ High house density level or overcrowding can increase the likelihood of interpersonal contacts, which is one way of transmission for pyoderma. ${ }^{1,2}$ However, in this study, house density level was not assessed.

There was no relation between socioeconomic levels with pyoderma incidence in this study. Most children with and without pyoderma in this study had low socioeconomic level. From the previously reported study conducted by Libu et al. ${ }^{4}$ in Kerala, there was no significant difference between socioeconomic level and skin disease. However, study conducted by Kharel et al. ${ }^{6}$ stated that there was significant risk ratio of socioeconomic status with recurrence of pyoderma. The different result from the two

Table 3 Relation between Personal Hygiene and Healthy Housing and Pyoderma Incidence

\begin{tabular}{lcccc}
\hline \multicolumn{1}{c}{ Characteristic } & $\begin{array}{c}\text { Pyoderma (+) } \\
\text { Mean }\end{array}$ & $\begin{array}{c}\text { Pyoderma (-) } \\
\text { mean }\end{array}$ & $\mathbf{p}$ & $\mathbf{9 5 \%} \begin{array}{c}\text { Confidence } \\
\text { Interval }\end{array}$ \\
Personal hygiene & 6.25 & 7.07 & $0.041^{*}$ & $0.06-1.59$ \\
Healthy housing & 904.8 & 1043.2 & 0.097 & $44.26-321.20$
\end{tabular}


previous study mentioned above might be caused by the different method that used to assess and determine socioeconomic level of subject. The previous study conducted by Kharel et al. ${ }^{6}$ in Nepal, used kuppuswamy scale to measure and determine socioeconomic level includes monthly wage, education level and occupation. Whereas this study only assessed monthly wage to determined socioeconomic level. The difference of method used might cause different result of socioeconomic level of the subjects.

This study also found that the educational level of parents was not related with pyoderma incidence. Study among primary school children in Kerala ${ }^{4}$ also found there was no significant association between education level of parents and skin disease, included pyoderma. However, study in Baghdad ${ }^{8}$ stated there was significant association between education level of parents and skin disease. This difference could be resulted from any other parental factor that was not assessed in this study, such as parental care and number of children in the family. Parental care would affect the child's hygiene. Number of children was significantly associated with skin disease in children. As the number of children increase, parental attention and care may decrease. ${ }^{4}$

This study had several limitations in the process. The first limitation of the study was recall bias. Subjects' parents may have difficulty in memorizing the particular conditions that were asked in the questionnaire. Therefore, their answers on the questionnaire might not accurate. The second limitation of the study was non response bias. Subjects' parents might give subjective answer on the questionnaire that differs from their actual condition. These conditions might happen in this study, because they did not want to be wrongly judged by their bad condition if they had given the real answers.

From this study, it could be concluded that personal hygiene is one of the risk factors that related with incidence of pyoderma among primary school children in Jatinangor sub district. The suggestion is school should make education program concerning cleanliness and hygienic life to students. It aims to prevent the occurrence of pyoderma. As well as education on the importance of treatment of pyoderma and pyoderma in students; therefore, students who are exposed will not transmit their disease. Furthermore, there is a need for further research to identify risk factors pyoderma by using different research designs.

\section{References}

1. Wolf K, Goldsmith LA, Katz SI, Gilchrest BA, Paller AS, Leffell DJ, editors. Fitzpatrick's dermatology in general medicine. 7th ed. New York: McGraw-Hill companies; 2008. p.1689-709.

2. WHO. Epidemiology and management of common skin disease in children in developing countries. Geneva: WHO; 2005. p. 4-19.

3. Gandhi S, Ojha AK, Ranjan KP, Neelima. Clinical and bacteriological aspects of pyoderma. N Am J Med Sci. 2012;4(10):492-5.

4. Libu, Bina T, Raphael L, E.Balakrishnan S, George B, Samson JF, et al. Prevalence and socio-demographic determinants of skin disease among lower primary school children in Calicut, Kerala. Kerala Med J. 2010;10(5):185-90.

5. Emodi IJ, Ikefuna AN, Uchendu U, Duru UA. Skin disease among children attending the out patient clinic of the university of Nigeria Teaching Hospital, Enug. Afr Health Sci. 2010;10(4):362-6.

6. Kharel C, Pandey SS, Agrawal S, Bhattarai M. Socioeconomic and nutritional status of children with pyodermas. NJDVL. 2012;10(1):11-5.

7. Sutisna IA, Harlisa P, Zulaikhah ST. Hubungan antara hygiene perorangan dan lingkungan dengan kejadian pioderma. Sains Medika. 2011;3(1):24-30.

8. Khalifa KA, Al-Hadithi TS, Al-Lami FH, AlDiwan JK. Prevalence of skin disorders among primary school children in Baghdad governorate, Iraq. East Mediterr Health J. 2010;16(2):209-13.

9. Leekha S, Diekema DJ, Perencevich EN. Seasonality of staphylococcal infections. Clin Microbiol Infect. 2012;18(10):92733.

10. Turabelidze G, Lin M, Wolkoff B, Dodson D, Gladbach S, Zhu BP. Personal hygiene and methicillin-resistant Staphylococcus aureus infection. Emerg Infect Dis. 2006;12(3):422-7.

11. Amin T, Ali A, Kaliyadan F. Skin disorders among male primary school children in $\mathrm{Al}$ Hassa, Saudi Arabia: prevalence and sociodemographic correlates-a comparison of urban and rural populations. Rural Remote Health. 2011;11(1):1517.

12. El-Gilany AH, Fathy $\mathrm{H}$. Risk factor of reccurent furunculosis. Dermatol Online J. 2009;15(1):16.

13. Luby SP, Agboatwalla M, Feikin DR, 
Painter J, Billhimer W, Altaf A, et al. Effect of handwashing on child health: a randomised controlled trial. Lancet. 2005;366(9481):225-33.

14. Hazarika N. A clinico-epidemiological study of pyoderma in children. Nat J Res Com Med. 2012;1(4):178-241.
15. Rosita R, Soepardi J, Brahim R, Sitohang V, Zulkarnaen I, Sunaryadi, et al. Indonesia health profile 2010. In: Indonesia Ministry of Health Republic of Indonesia, editor. Jakarta: Ministry of Health Republic of Indonesia; 2011. p. 26. 